\title{
Factor structure and dimensionality of the balanced measure of psychological needs among Portuguese high school students. Relations to well-being and ill-being ${ }_{2}$ 出
}

\author{
Pedro Cordeiro ${ }^{\mathrm{a}, *}$, Paula Paixão ${ }^{\mathrm{a}}$, Willy Lens ${ }^{\mathrm{b}, \mathrm{c}}$, Marlies Lacante ${ }^{\mathrm{b}, \mathrm{c}}$, Kennon Sheldon ${ }^{\mathrm{d}}$ \\ a Faculty of Psychology and Educational Sciences, University of Coimbra, Portugal \\ ${ }^{\mathrm{b}} \mathrm{KU}$ Leuven, Belgium \\ c University of the Free State, South Africa \\ d Faculty of Psychological Sciences, University of Missouri, United States
}

\section{A R T I C L E I N F O}

\section{Article history:}

Received 12 January 2015

Received in revised form 4 December 2015

Accepted 22 December 2015

Available online $\mathrm{xxxx}$

\section{Keywords:}

Balanced measure of psychological needs

Self-determination theory

Confirmatory factor analysis

Regression analysis

Well-being

Ill-being

\begin{abstract}
A B S T R A C T
Previous research on the Balanced Measure of Psychological Needs Scale (BMPN) fitted a 5-factor structure distinguishing the three need factors of autonomy, competence and relatedness and the two method factors of need satisfaction and dissatisfaction. The current study explores the dimensionality and construct validity of the Portuguese version of the Balanced Measure of Psychological Needs (Sheldon \& Hilpert, 2012) in two samples of high school students. We compared the original 5 -factor model to three alternative models to assess the ability of each model to represent the factorial organization of the data. Confirmatory factor analysis yielded a good fit for solutions that separately modeled the satisfaction and frustration components of needs. The best-fitting solution of six factors, one per subscale, was supported in both high school samples, and was also shown by multigroup analysis to be invariant across gender. Regression analyses found that basic need satisfaction was related to subjective vitality and satisfaction with life $(\mathrm{SWL})$ and need dissatisfaction predicted anxiety, depression and somatization. The substantive distinction between the satisfaction and frustration components of needs, and implications for educational settings, are discussed. Overall, the Portuguese BMPN appears to be reliable and valid to measure basic need satisfaction and need frustration for Portuguese high school students.
\end{abstract}

(c) 2015 Elsevier Inc. All rights reserved.

\section{Introduction}

Self-Determination Theory (Deci \& Ryan, 2000, 2008) is a macroorganismic theory of motivational and personality development that proposes innate, universal, psychological needs as key motivational constructs (Deci \& Ryan, 1985). For SDT, experiences of autonomy, competence and relatedness satisfaction are postulated to be innately rewarding experiences that energize behavior and help people develop greater integrity and well-being (e.g., Deci \& Ryan, 2000; Reis, Sheldon, Gable, Roscoe, \& Ryan, 2000). Autonomy satisfaction is the experience of self-endorsement, volition and choice in the initiation and regulation of behavior (e.g., Deci \& Ryan, 1985), competence satisfaction corresponds to the feelings of being skilled and competent to master various challenges (e.g., Deci \& Ryan, 1985; Schunk \& Zimmerman, 2006), and relatedness satisfaction is expressed in the feelings of being emotionally connected to others within warm, supportive and caring interpersonal relations (Baumeister \& Leary, 1995; Ryan, 1995). On

\footnotetext{
is This research was fully supported by the first author's scholarship from the Foundation for Science and Technology - Portugal.

* Corresponding author.

E-mail address: pedrcordeiro@gmail.com (P. Cordeiro).
}

the other hand, the dissatisfaction of each need corresponds to the subjective experiences of low satisfaction of autonomy, competence and relatedness needs.

For SDT the inner experience of need satisfaction/dissatisfaction is distinct from the experience of need frustration for different reasons (Deci \& Ryan, 2000; Vansteenkiste \& Ryan, 2013). Firstly, the subjective experience of need frustration is characterized by distinct features. Autonomy frustration relates to perceptions of being controlled through externally enforced or self-imposed pressures (perception of pressure from teachers, or from self-imposed high standards for achievement), competence frustration expresses feelings of incompetence and failure to accomplish achievement-related goals (perception of not having the skills to succeed in school) and relatedness frustration is associated with the experience of relational exclusion and loneliness (perception of being different or apart from others). Secondly, need satisfaction and frustration seem to be rooted in distinct social experiences. Need satisfaction is experienced in social milieus that actively foster or support the three needs (e.g., the teacher provides effort-based praise for the good grade), need dissatisfaction develops from "passive" socialization styles that deprive the child from the basic nutriments necessary for need satisfaction (e.g., the teacher does not involve the students in the organization of class activities) and need frustration grows from 
more "directive" educational styles that actively and chronically thwart the satisfaction of needs (e.g., the teacher uses guilt-induction when the student's grade does not meet his/her standards; Deci \& Ryan, 2008; Sheldon, 2011; Vansteenkiste \& Ryan, 2013). Thirdly, experiences of need frustration have been also distinguished from experiences of need satisfaction and dissatisfaction for their unique effects on motivational criteria (Deci \& Ryan, 1985; Vansteenkiste \& Ryan, 2013). Need satisfaction primarily relates to well-being and optimal integrated functioning (e.g.,Sheldon \& Niemiec, 2006; Ryan \& Deci, 2000; Sheldon, Ryan, \& Reis, 1996), need dissatisfaction positively predicts feelings of low well-being, but not necessarily experiences of ill-being (e.g., Bartholomew, Ntoumanis, Ryan, \& Thøgersen-Ntoumani, 2011; Quested \& Duda, 2010), whereas need frustration predicts ill-being/ psychopathology and low well-being (e.g., Bartholomew et al., 2011; Vansteenkiste, Lens, Soenens, \& Luyckx, 2006). Taking into account their different developmental roots, nature and unique effects on psychological criteria, SDT suggests that need frustration should not be equated with need dissatisfaction, or with the extreme pole of the need satisfaction continuum. This distinction has important implications for the measurement of psychological needs.

\subsection{Measurement of basic needs}

SDT-based measures of psychological needs have recently evolved to include separate item sets that assess the subjective experiences of psychological need satisfaction/dissatisfaction (indexed by positivelyworded items) and of need frustration (indexed by negatively-worded items). Among the most well-validated are the Balanced Measure of Psychological Needs Scale (BMPN; Sheldon \& Hilpert, 2012), the Basic Psychological Need Satisfaction and Frustration Scale (BPNSFS; Chen et al., 2015), and the domain-specific Psychological Need Thwarting Scale - PNTS (Bartholomew et al., 2011).

The BMPN (Sheldon \& Hilpert, 2012) is generally used as three separate but distinguishable autonomy, competence, and relatedness subscales that measure the subjective experiences of need satisfaction for life as a whole. The internal structure of the BMPN was validated in a $3 \times 2$ model. Three factors distinguish the autonomy, competence and relatedness need satisfaction. Two additional method factors distinguish the satisfaction (scores of positively-worded items) and dissatisfaction poles (scores of negatively-worded items) of the need satisfaction continuum. Following a different conceptualization, the BPNSFS (Chen et al., 2015) measures the satisfaction and frustration components of the three needs as substantively distinct constructs. The BPNSFS was validated for a 6-factor model. Three scales, of 12 positively-worded items, assess autonomy, competence and relatedness need satisfaction, and three other scales, of 12 negatively worded items, assess the frustration of each need. Finally, the PNTS (Bartholomew et al., 2011), a domain-specific measure of the needs developed for the sports context, assess, in three separate scales, the subjective experiences of autonomy, competence and relatedness need thwarting. At this purpose, two issues are noteworthy. As we can see the three scales used conceptually diverse labels to describe the subjective negative experiences related to basic needs, defined as need dissatisfaction (Sheldon \& Hilpert, 2012), need frustration (Chen et al., 2015) or need thwarting (Bartholomew et al., 2011).

In addition, the dissatisfaction, thwarting and frustration components of needs, measured with reverse-scored negative items were examined either as opposite poles of need satisfaction (Sheldon \& Hilpert, 2012) or as substantively distinct from need satisfaction (Bartholomew et al., 2011; Chen et al., 2015). Yet, to date, the comparative fit of the three models altogether was not yet performed for the BMPN, leaving unanswered the question of whether need frustration (dissatisfaction or thwarting) and satisfaction of needs are distinguished by virtue of statistical artifacts or, in fact, correspond to substantive constructs.

For conceptual clarity, in this paper we use the term need thwarting to reflect influence of contexts that block the needs' satisfaction (Ryan,
1995) and need frustration to describe the inner feelings that develop from these experiences (Vansteenkiste \& Ryan, 2013). Moreover, in line with Chen et al., (2015) we interpreted the negatively-worded items as indicators of need frustration, and examined whether the satisfaction and frustration components of autonomy, competence and relatedness needs are best interpreted as separate constructs, or as opposite poles of the need satisfaction continuum. To attain this goal we compared four non-nested models for model fit. Fig. 1 provides a graphic portrayal of the four models tested in CFA.

Model 1 (Deci \& Ryan, 2000) organized the six BMPN scales into three latent factors, that distinguish the three psychological needs, assuming that the satisfaction and dissatisfaction components of needs lie within the need satisfaction continuum. For parsimony, Factor 1 assesses autonomy satisfaction versus autonomy dissatisfaction; Factor 2, competence satisfaction versus competence dissatisfaction and Factor 3 , relatedness satisfaction versus relatedness dissatisfaction. Best-fit of Model 1 suggests, in line with more traditional perspectives, that the satisfaction and dissatisfaction components of needs are opposite poles of the need satisfaction continuum, with need dissatisfaction being equated as the lack of need satisfaction (e.g., Hodge, Lonsdale, \& $\mathrm{Ng}, 2008$ ).

In addition, Model 2 (Sheldon \& Hilpert, 2012), adds to the structure of the three factors described for Model 1, two additional method factors assessing the satisfaction (indicated by nine positively-worded items) and dissatisfaction of needs (indicated by nine negativelyworded items). Best-fit for Model 2 supports the tripartite structure of basic needs posited by SDT (Deci \& Ryan, 2000), controlling for potential bias associated to the shared method variance of positively and negatively-worded items (Sheldon \& Hilpert, 2012).

In Model 3 we modeled the negatively-worded BMPN scales as substantively distinct measures of autonomy, competence and relatedness need frustration, with need satisfaction and need frustration representing two different motivational continuums. In this model the BPNSFS is organized in a two-factor higher-order need satisfaction and need dissatisfaction latent factors, each indicated by three first order factors of autonomy, competence and relatedness satisfaction (e.g., Haerens, Aelterman, Vansteenskiste, Soenens, \& Petegen, 2015). Best-fit for Model 3 asserts the substantive nature of the satisfaction and dissatisfaction components of needs.

Finally, Model 4 (Chen et al., 2015) arranged the six scales in six latent factors that distinguish the components of satisfaction ( 3 scales) and frustration ( 3 scales) for autonomy, competence and relatedness needs. Best fit for Model 4 extends the structural distinction between need satisfaction and frustration (Model 3 ) to each of the three needs (Bartholomew et al., 2011; Chen et al., 2015).

\subsection{Present study and hypotheses}

To examine this premise, we re-examined the internal structure of the BMPN in Study 1, to ascertain whether the six scores of satisfaction and frustration of the three needs should be best interpreted as two general method factors reflecting the positively/negatively wording of items (as in Sheldon \& Hilpert, 2012), two higher-order substantive factors of need satisfaction and frustration (as in Bartholomew et al., 2011) or six substantive factors distinguishing the satisfaction and frustration components of each need (Chen et al., 2015). In so doing we fitted the BMPN data to four competitive models, conceptualizing the components of satisfaction and frustration of psychological needs as opposite dimensions (Model 1), as distinct method effects (Models 2) or as substantively distinct constructs (Models 3 and 4). We expect the good fit of Models 2, 3 and 4 but the poor fit of Model 1, under the assumption that need frustration is distinct (versus opposite) of need satisfaction (Hypothesis 1a; see also Bartholomew et al., 2011; Deci \& Ryan, 2000; Sheldon \& Gunz, 2009; Vlachopoulos \& Michailidou, 2006). In addition we expect the progressive better fit from Models 2 to 4 , as the distinction moves from distinct need satisfaction and frustration as method 


\section{Model 1}

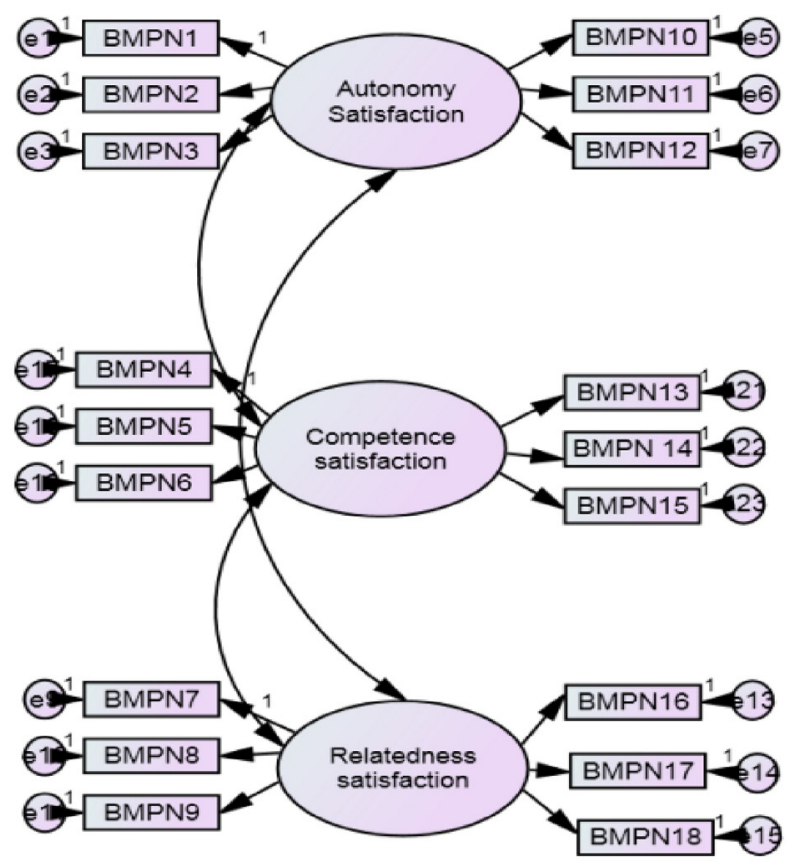

Model 3

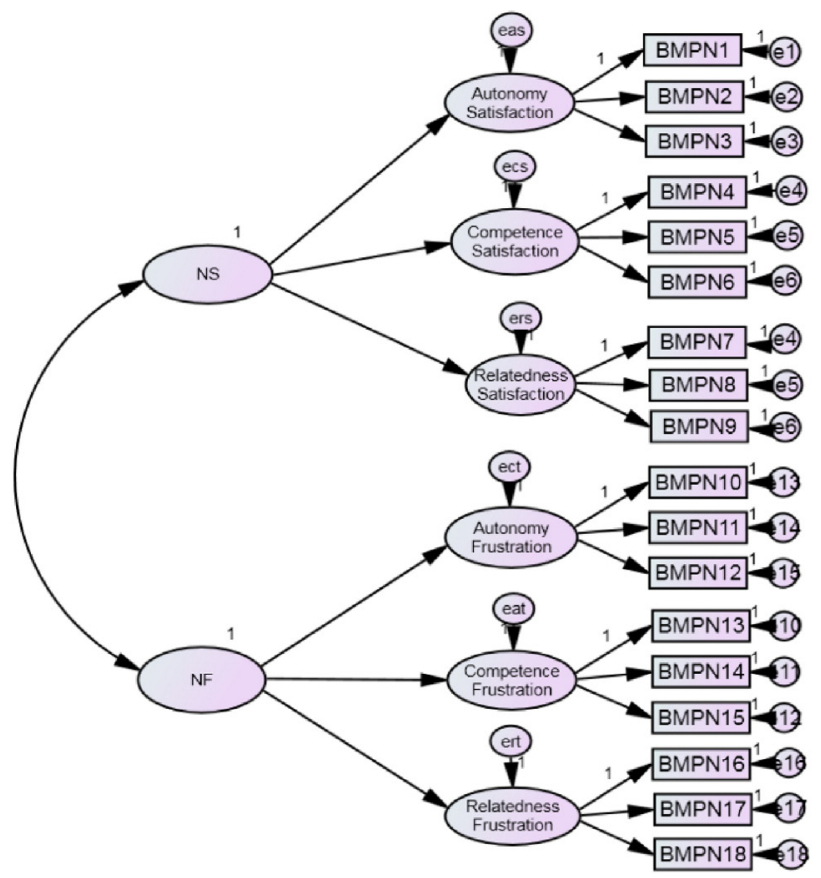

Model 2

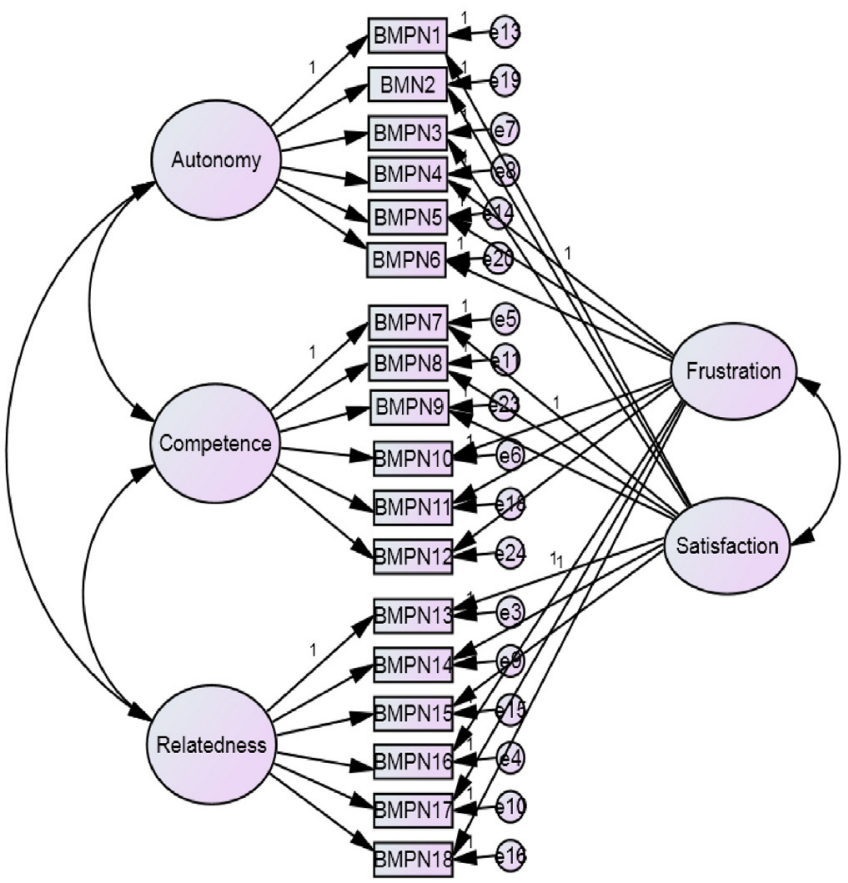

Model 4

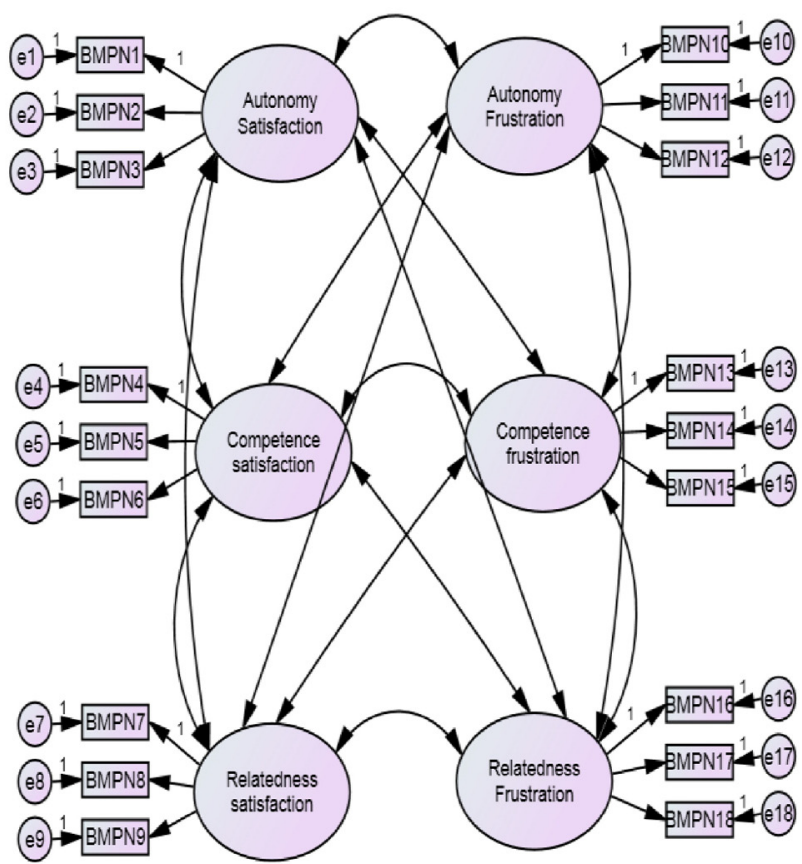

Fig. 1. Graphic portrayal of the CFA models. First panel: Model 1 (left) and Model 2 (right). Second panel: Model 3 (left) and Model 4 (right).

effects to substantively distinct constructs (Hypothesis $1 \mathrm{~b}$ ). The bestfitting measurement model (here expected to be Model 4) was further examined in terms of internal consistency, considering the composite reliability $(C R)$ of the scores. Construct validity was further examined from estimates of convergent validity $(C V)$ and discriminant validity $(D V)$ to ascertain whether the 18 items converge to measure as to 
discriminate, the six latent constructs under analysis. If the six-factor solution of scales is, as assumed, adequate to interpret the theoretical structure of the BMPN we would expect no threats to reliability or to the validity of the six scales (Hypothesis 2). Further, we would expect that the six scales related uniquely to the outcomes.

Thus, in Study 2 we examined the criterion-related validity of the expected best-fitting 6-factor model of scales, in an independent sample of high school students. As a pre-condition to proceed into further analysis we expect that the subjective experiences of need frustration predict students' adjustment over and above need satisfaction (Hypothesis 3, Bartholomew et al., 2011). More specifically, in line with Chen et al. (2015) we hypothesize that the satisfaction of the three needs positively predicts SWL and subjective vitality (Hypothesis $4 a$ ), controlling for need frustration, whereas the frustration of the three needs will positively predict anxiety, depression and somatization (Hypothesis $4 b$ ), controlling for need satisfaction. Additionally, consistent with recent research (Adie, Duda, \& Ntoumanis, 2008) we expect that need satisfaction does not significantly relate to anxiety, depression and somatization after controlling for need frustration (Hypothesis $4 c$ ), whereas need frustration will be significantly negatively associated to SWL and subjective vitality after controlling for need satisfaction (Hypothesis $4 d$ ).

\subsection{Plan of analyses and statistics}

In Study 1 we report the procedures followed to develop the Portuguese version of BMPN. Next, we describe the analytical procedures used to investigate the internal structure of the BMPN. In a first step we used exploratory factor analyses (EFA; Mclver \& Carmines, 1981 ) with principal components (PCA) and varimax orthogonal to explore the dimensionality of the BMPN items. In a second step we performed a confirmatory factor analysis (CFA; Byrne, 2010) on the BMPN items, on four competitive models and evaluated their fit. Model fit was judged from multiple fit indices, including the Chi square test $\left(\chi^{2}\right)$, the standardized root mean square residual (RMR), the comparative fit index (CFI) and the root mean squared error of approximation (RMSEA). Goodness-of-fit used the combined cut-off values of 0.09 for SRMR, 0.06 for RMSEA P [rmsea $\leq 0.05]$ and $\geq 0.90$ for CFI (Hu \& Bentler, 1999). The factors were allowed to correlate, but no item crossloadings or correlated error variances were allowed. To select the preferred model, we relied in Akaike's information criteria with the lowest values indicating the preferred model (<AIC; Kline, 2005). All estimates were computed in AMOS 20.0 (Amos Development Corporation, Florida, US). In a third step we examined model fit and the psychometric properties of the scales. Estimates of composite reliability ( $C R \geq .70$ ), convergent validity (average variance extracted $[A V E] \geq 0.5$ ) and discriminant validity (maximum shared squared variance $[M S V]<[A V E]<$ average shared squared variance $[A S V]<A V E)^{1}$ were obtained from the $C F A$ correlation matrix (Fornell \& Larcker, 1981) and from standardized regression weights (e.g., Bartholomew et al., 2011). In a fourth step we examined the cross-gender invariance of the model that best-fitted the BMPN data. A sequential model testing approach was followed, with two models specified: an unconstrained model (where factor loadings were allowed to vary between boys and girls) was compared to two increasingly constrained models, where factor loadings (measurement equality model) and factor variances and co-variances (structural parameters model) were set equal across the sexes (Byrne, 2010). Model invariance was indicated by the $\chi^{2}$ difference test and the CFI difference approach $(\triangle C F I<.01$; Cheung \& Rensvold, 2002). In a fifth step (Step 1 of Study 2) we fitted the best-fitting model in Study 1 to an independent sample of 12th grade students, in order to generate cross-validation evidence. CFA with maximum likelihood estimation was performed. In a sixth step (Step 2 of Study 2) we computed multivariate multiple

\footnotetext{
${ }^{1}$ Discriminant validity was achieved when the average variance extracted obtained for each scale was greater than the squared correlation estimates of each pair of latent constructs.
}

regression analyses to examine whether the six need-factors predict unique variance on well-being and ill-being outcomes (external validity; for similar approaches see Chen et al., 2015; Verstuyf, Vansteenkiste, Soenens, Boone, \& Mouratidis, 2013). Finally, in a seventh step (Step 3 of Study 2) we performed a hierarchical multiple regression analysis to examine whether need frustration added value to need satisfaction in the prediction of well/ill-being outcomes.

\section{Study 1}

\subsection{Participants and procedure}

Sample 1 included 371 students (grade 10: $n=101$ [27, 2\%], grade $11: n=148[39,9 \%]$, grade $12 n=122[32,9 \%])$, of both sexes (male: $n=171$ [43, 8\%], female $n=200$ [56, 2\%]), aged between 16 and 23 years old $(M=18 ; S D=1,309)$. Students attended scientifichumanistic $(n=153[41,2 \%])$ or technical-vocational courses $(n=$ $218[58,8 \%])$ in three private $(n=189[50,9 \%])$, and two state run $(n=182[49,1 \%])$ schools. A total of 15 classes was involved in the study. The Portuguese version of the BMPN was administered in the Portuguese secondary schools, after informed consent was obtained from students or parents of underage students and authorizations were guaranteed from the National Board of Education. The scale was group-administered by the primary researcher during regular school hours. Instructions were read aloud and aspects such as the voluntary participation and confidentiality of the data were secured by the researcher. Students took about 15 min to complete the survey. None of the participants refused collaboration and credits were not given for participation.

\subsection{Measures}

\subsubsection{Psychological need satisfaction}

The Portuguese version of the 18-item Balanced Measure of Psychological Needs (Sheldon \& Hilpert, 2012) was used in this study. The BMPN comprises six 3-item subscales measuring autonomy satisfaction (F1: items 1, 2, 3; e.g., "My choices are based on my true interests and values"), competence satisfaction (F2: items 4, 5, 6; e.g., "I am successful at completing difficult tasks and projects") and relatedness satisfaction (F3: items 7, 8, 9; e.g., "I feel a sense of contact with people who care for me, and whom I care for"). Three additional three-item subscales measure autonomy dissatisfaction (F4: items 10,11, 12; e.g. "I do things against my will”), competence dissatisfaction (F5: items 13, 14, 15; e.g., "I do stupid things, that make me feel incompetent"), and relatedness dissatisfaction (F6: items 16, 17, 18; e.g., "I feel unappreciated by one or more important people"). A 5-point Likert scale, ranging from $1=$ no agreement to $5=$ much agreement, was used to rate the items. In the original studies the internal consistency reported for the six scales ranged between .71 and .85 for positively and negatively worded relatedness, $\alpha=.71$ and $\alpha=.70$ for positively and negatively worded competence, and $\alpha=.69$ and $\alpha=.72$ for positively and negatively worded autonomy (Sheldon \& Hilpert, 2012).

\subsection{Questionnaire translation}

The 18-item BMPN was translated into Portuguese using the backtranslation technique (Hambleton, 2001). Portuguese-speaking researchers, fluent in English, collaborated with a professional interpreter to translate the scale from English into Portuguese. Then an independent interpreter translated the scales back into English. Next, the original and back-translated versions of the scale were checked for accuracy, and non-equivalent translations were discussed until a final version was agreed. The readability and unambiguous understanding of the items was then checked in a pilot study using a sample of eleven Portuguese 10th grade students. Following the students' feedback, we modified two items in both wording and syntax (e.g., The Portuguese translation 
of the expression "true self" in item 3 was modified to ... "express truly who I am").

\subsection{Preliminary results}

\subsubsection{Normality of the distribution}

Table 1 presents the descriptive statistics and factor loadings of the BMPN items. In a preliminary analysis we screened the normality of the distribution of the P-BMPN items (Sample $1 ; N=371$ ), at the univariate and multivariate levels. Missing data was dealt by mean replacement. The distribution of the BMPN items was approximately normal in terms of univariate Skewness and Kurtosis, but the multivariate kurtosis coefficient departed significantly from normality ( $k u M=48.55$; Bentler \& Wu, 2002, cited in Finney \& DiStefano, 2006). Therefore, in all further analyses we used 1000 bootstrap samples with replacement based on the original sample (Preacher \& Hayes, 2004).

\subsection{Primary results}

\subsubsection{Exploratory factor analysis}

EFA (Mclver \& Carmines, 1981) in principal components (PCA) and Promax Rotation was performed $(N=371)$ to determine the internal structure of the BMPN scale. PCA on the 18 items yielded six components with eigenvalues larger than 1 (Tinsley \& Tinsley, 1987, see Table 1$)$. The six factors explained $18,63 \%, 12,31 \%, 10,17 \%, 9,82 \%, 6$, $39 \%$, and $6,36 \%$ of the variance, respectively, and altogether they accounted for $63.69 \%$ of the total variance explained. All factors presented good internal consistency: autonomy satisfaction ( $\alpha=.84)$, competence satisfaction $(\alpha=.79)$, relatedness satisfaction $(\alpha=.82)$, autonomy frustration ( $\alpha=.85)$, competence frustration $(\alpha=.82)$, and relatedness frustration $(\alpha=.77)$ and the corrected item-total correlations of the six factors were in a satisfactory range (.68-.70; .59-. 74; $.69-.74 ; .64-.72 ; .62-.72 ; .46-.51$, respectively). Furthermore, all scale items loaded significantly on the intended factors $(\lambda \mathrm{ij}>0.5$; $\lambda 2 \mathrm{ij} \geq 0.25, p<.05$ ), suggesting the factorial validity of the six scales.

\subsubsection{Confirmatory factor analysis}

Table 2 summarizes the goodness-of-fit results for the four competitive models. CFA results show a poor fit of Model 1 across all the fit indices considered $\chi^{2}(249)=1263.66 ; p<.001 ; C F I=.69 ;$ RMSEA $=.14$ $P[$ rmsea $\leq 0.05]<0.001 ; R M R=.10$. Models 2,3 and 4 showed an adequate fit to the data (see Table 4 ) with a progressive better fit observed from Model 2 to Model 4. The best fit of Model $4 \chi^{2}(120)=185.54$; $p<.001 ; C F I=.96 ; R M S E A=.04 P[$ rmsea $\leq 0.05]<0.001 ; R M R=.04$, along with the lowest AIC estimates, guided our option to use it in further analyses.

\subsubsection{Cross-gender invariance analysis}

A subsequent multigroup confirmatory factor analysis examined the metric invariance of the Model 4 across gender (see Table 3 for a summary of model estimates). The unconstrained model yielded an adequate fit to the BMPN data, $\chi^{2}(299)=399.73$, with all factor loadings being statistically significant. The unconstrained and the constrained models were not significantly different $(\chi 2<.001 ; C F I<.01)$, providing evidence for the gender invariance in terms of factor loadings and structural covariances.

\subsubsection{Reliability and validity}

Table 3 presents estimates of reliability and validity for the six-factor factors solution. Adequate reliability was also found for the six BMPN factors, with composite reliability coefficients ranging from .72 to .81. In terms of the validity of the scores, positive correlations found between the three factors measuring need satisfaction and also across the three factors assessing need frustration, suggest the convergent validity of the measures (all $A V E \geq 0.5$ ). Further, the negative correlations found between the satisfaction and frustration scores for each need support the discriminant validity of the six constructs (MSV $<A V E<A S V<A V E)$. All correlations were weak to moderate (from $r=.16, p<.01$ to $r=.35$, $p<.001$ ) indicating that multicollinearity was unlikely to be a problem (see Tabachnick \& Fidell, 2007). Overall, the associations between the six constructs present no threats to both convergent and discriminant

Table 1

Item means, standard deviations, skewness and kurtosis, factor loadings and communalities for the P-BMPN (Study 1).

\begin{tabular}{|c|c|c|c|c|c|c|c|c|c|c|c|}
\hline \multirow[t]{2}{*}{ BMPN subscale and item } & \multirow[t]{2}{*}{$M$} & \multirow[t]{2}{*}{$S D$} & \multirow[t]{2}{*}{ SK } & \multirow[t]{2}{*}{ Ku } & \multicolumn{6}{|c|}{$\begin{array}{l}F L \\
\left(\lambda_{i j} \geq 0.5 ; \text { CI 95\%) }\right.\end{array}$} & \multirow[b]{2}{*}{$R^{2}$} \\
\hline & & & & & F1 & $\mathrm{F} 2$ & F3 & F4 & F5 & F6 & \\
\hline \multicolumn{12}{|l|}{ F1. Autonomy satisfaction } \\
\hline 1. My choices are based on my true interests and values & 4.22 & .83 & 1.20 & .67 & .78 & - & - & - & - & - & 63 \\
\hline 2. I feel free to do things my own way & 3.72 & .95 & -.99 & .60 & .83 & - & - & - & - & - & .62 \\
\hline 3. My choices express my true self & 4.10 & .83 & -1.20 & 1.38 & .78 & - & - & - & - & - & .61 \\
\hline \multicolumn{12}{|l|}{ F2. Competence satisfaction } \\
\hline 4. I am successful at completing difficult tasks and projects & 3.74 & .82 & -.68 & .10 & - & .73 & - & - & - & - & .71 \\
\hline 5. I am taking on mastering hard challenges & 3.95 & .80 & -.36 & -.41 & - & .89 & - & - & - & - & .65 \\
\hline 6. I am very capable in what I do & 3.78 & .81 & .16 & -.62 & - & .65 & - & - & - & - & .66 \\
\hline \multicolumn{12}{|l|}{ F3. Relatedness satisfaction } \\
\hline 7. I feel a sense of contact with people who care for me and whom I care for & 4.33 & .81 & -.88 & .32 & - & - & .81 & - & - & - & .76 \\
\hline 8. I feel close and connected with other people who are important to me & 4.32 & .89 & -1.01 & .67 & - & - & .82 & - & - & - & .77 \\
\hline 9. I feel a strong sense of intimacy with the people I spend time with & 4.11 & .93 & 1.65 & 2.06 & - & - & .71 & - & - & - & .76 \\
\hline \multicolumn{12}{|l|}{ F4. Autonomy frustration } \\
\hline 10. I have a lot of pressures I could do without & 3.66 & 1.12 & 1.22 & .60 & - & - & - & .70 & - & - & .60 \\
\hline 11. There are people telling me what I have to do & 3.17 & 1.23 & .79 & -.35 & - & - & - & .86 & - & - & .50 \\
\hline 12. I do things against my will & 2.77 & 1.25 & .78 & -.13 & - & - & - & .88 & - & - & .51 \\
\hline \multicolumn{12}{|l|}{ F5. Competence frustration } \\
\hline 13. I do stupid things that make me feel incompetent & 2.71 & 1.24 & .92 & .24 & - & - & - & - & .80 & - & .60 \\
\hline 14. I often experience failure or find myself unable to do well at something & 2.61 & 1.20 & .84 & -.08 & - & - & - & - & .83 & - & .58 \\
\hline 15. I struggle doing things I should be good at & 4.20 & .78 & 1.20 & .67 & - & - & - & - & .71 & - & .77 \\
\hline \multicolumn{12}{|l|}{ F6. Relatedness frustration } \\
\hline 16. I am lonely & 2.10 & 1.20 & -1.20 & 1.38 & - & - & - & - & - & .66 & .59 \\
\hline 17. I feel unappreciated by one or more important people & 2.52 & 1.33 & -1.04 & .47 & - & - & - & - & - & .79 & .61 \\
\hline 18. I have disagreements or conflicts with important people & 2.59 & 1.30 & -.68 & .10 & - & - & - & - & - & .70 & .54 \\
\hline Multivariate kurtosis & & & & 48.55 & & & & & & & \\
\hline Total variance explained (\%) & & & & & 18.60 & 12.31 & 10.17 & 9.82 & 6.39 & 6.36 & \\
\hline
\end{tabular}

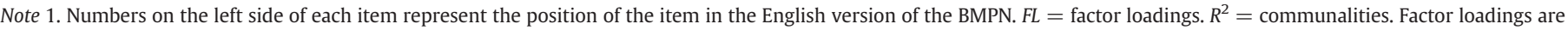
statistically significant at $p<.05$.

$N=371$. 
Table 2

Goodness-of-fit index for the four models tested. Multiple-group analysis for Model 3 (Study 1 ).

\begin{tabular}{|c|c|c|c|c|c|c|c|c|c|c|c|}
\hline \multirow[t]{2}{*}{ Model } & \multirow[t]{2}{*}{$\chi^{2}$} & \multirow[t]{2}{*}{$\chi^{2} / d f$} & \multirow[t]{2}{*}{ CFI } & \multirow[t]{2}{*}{ GFI } & \multirow[t]{2}{*}{ RMSEA } & \multirow[t]{2}{*}{$R M R$} & \multirow[t]{2}{*}{ AIC } & \multicolumn{4}{|c|}{ Comparison of models } \\
\hline & & & & & & & & $\Delta \chi^{2}$ & $\Delta d f$ & P-value & $\triangle C F I$ \\
\hline \multicolumn{12}{|c|}{ Confirmatory factor analysis (Study 1) } \\
\hline Model 1-3-factor model & 1263.66 & 9.57 & .69 & .71 & .14 & .10 & 1341.66 & & & & \\
\hline Model 2-5-factor model & 436.44 & 3.81 & .92 & .90 & .08 & .06 & 550.44 & & & & \\
\hline Model 3-2-factor model & 236.81 & 1.99 & .97 & .95 & .05 & .04 & 340.90 & & & & \\
\hline Model 4-6-factor model & 185.54 & 1.55 & .96 & .95 & .04 & .04 & 287.54 & & & & \\
\hline \multicolumn{12}{|c|}{ Confirmatory factor analysis (Study 2) } \\
\hline Model 4-6-factor model & 269.32 & 1.55 & .95 & .94 & .05 & .05 & 371.32 & & & & \\
\hline \multicolumn{12}{|c|}{ Multiple-group analysis (Study 1) } \\
\hline Unconstrained & 329.12 & 1.29 & .957 & .91 & .03 & .06 & & & & & \\
\hline Measurement weights & 343.22 & 1.28 & .956 & .91 & .03 & .06 & & $\Delta \chi^{2}=14.10$ & $\Delta d f=12$ & .30 & .001 \\
\hline Structural weights & 354.87 & 1.30 & .953 & .90 & .03 & .06 & & $\Delta \chi^{2}=25.75$ & $\Delta d f=18$ & .11 & .004 \\
\hline Structural covariances & 354.93 & 1.29 & .953 & .90 & .03 & .06 & & $\Delta \chi^{2}=25.81$ & $\Delta d f=19$ & .14 & .004 \\
\hline Structural residuals & 363.91 & 1.30 & .941 & .89 & .03 & .06 & & $\Delta \chi^{2}=34.79$ & $\Delta d f=25$ & .09 & .002 \\
\hline Measurement residuals & 399.73 & 1.34 & .943 & .89 & .03 & .06 & & $\Delta \chi^{2}=70.61$ & $\Delta d f=43$ & .01 & .001 \\
\hline
\end{tabular}

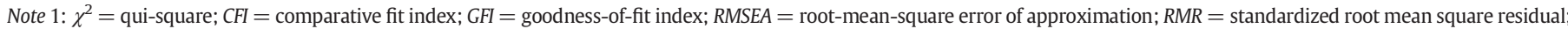

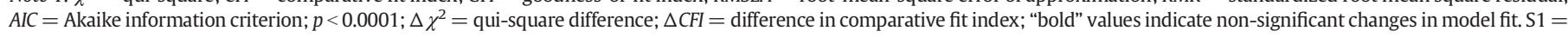
Sample $1(N=371)$.

validity, suggesting the adequacy of the six-factor solution to interpret the factorial distribution of the BMPN items (see also Table 2).

\section{Study 2}

\subsection{Participants and procedure}

A convenience sample of 12 th grade high school students $(N=366)$ aged between 16 and 21 years, with a mean age of 17,25 years $(S D=0$, 90) completed the questionnaires. The participants were of both sexes (male: $n=80$ [40\%], female $n=120$ [60\%]), aged between 16 and 22 years old $(M=18,38 ; S D=.75)$. Students attended regular high school scientific-humanistic courses in Portuguese public schools. Scale administration and ethical procedures were as described in Study 1 .

\subsection{Measures}

\subsubsection{Psychological need satisfaction}

The Portuguese version of the BMPN was used, as above described.

\subsubsection{Well-being}

The Portuguese version of the Satisfaction With Life Scale - SWLS (Diener, Emmons, Larsen, \& Griffin, 1985, $\alpha=.87$; Portuguese version, Simões, $1992, \alpha=.77$ ) was used to measure the cognitive component of subjective well-being (e.g., "I am satisfied with my life"). Additionally we used the 5-item Portuguese version of the Subjective vitality $=.04 P$ $[R M S E A \leq 0.05]<0.001$ Scale (Ryan \& Frederick, 1997, $\alpha=.84$;

Table 3

Composite reliability, convergent and discriminant validity of the six BMPN subscales (Study 1).

\begin{tabular}{|c|c|c|c|c|}
\hline \multirow[t]{2}{*}{ BMPN subscales } & \multirow{2}{*}{$\begin{array}{l}\text { Composed } \\
\text { reliability }\end{array}$} & \multirow{2}{*}{$\begin{array}{l}\text { Convergent } \\
\text { validity }\end{array}$} & \multicolumn{2}{|c|}{$\begin{array}{l}\text { Discriminant } \\
\text { validity }\end{array}$} \\
\hline & & & MSV & $A S V$ \\
\hline 1. Autonomy satisfaction & .84 & .64 & .30 & .22 \\
\hline 2. Competence satisfaction & .80 & .58 & .23 & .14 \\
\hline 3. Relatedness satisfaction & .83 & .61 & .30 & .20 \\
\hline 4. Autonomy frustration & .85 & .66 & .45 & .21 \\
\hline 5. Competence frustration & .82 & .61 & .45 & .25 \\
\hline 6. Relatedness frustration & .72 & .54 & .19 & .12 \\
\hline
\end{tabular}

Note: Convergent validity (AVEi $\geq 0.5)$; composite reliability $(C R \geq 0.7)$. Discriminant validity $\left(R^{2}\right)$; average variance extracted $(A V E) ; M S V=$ maximum shared squared variance; $A S V=$ average shared squared variance.
Portuguese version, Lemos, Gonçalves \& Coelho, $2011 ; \alpha=.86$ ) to evaluate how alive and alert people have been feeling during the last month (e.g., "I feel alive and vital"). Both scales were rated in a Likert-type 5-point scale, ranging from 1 ("Completely untrue/Not at all true") to 5 ("Completely true/Very true"). In the current sample, the unidimensional model estimated for SWL $\chi^{2}(5)=10,27 p<.001$; CFI = .99; RMSEA; $S R M R=.02)$ and for SV $\chi^{2}(9)=68.73 p<.001 ; C F I=.97 ; R M S E A=$ $.09 P[$ rmsea $\leq 0.05]<0.001 ; S R M R=.03)$ yielded a good fit to the data. Items of both scales loaded above .60 and good internal consistency was found for both SWL $(\alpha=.81)$ and for SV $(\alpha=.81)$.

\subsubsection{Ill-being}

The Portuguese version of the 18-item Brief Symptom Inventory (BSI-18; Derogatis, 2001; Portuguese version, Canavarro, 2007) was used to assess the psychological symptoms of anxiety (e.g., "Feeling tense or keyed up"), depression (e.g., "Feeling lonely") and somatization (e.g., "Pains in heart or chest"). The BSI-18 is rated on a 4-point Likert scale of distress, ranging from 1 ("Not at all") to 5 ("Extremely"). The internal consistency reported for the 9 subscales ranged between .70 for somatization, .89 for depression (Derogatis, 2001) and between .62 and .80 for the Portuguese version (Canavarro, 2007). In the current sample, CFA on the multidimensional model of three scales showed a good fit to the data $\chi^{2}(60)=170,02 p<.001 ; C F I=.96 ; G F I=.95$; $R M S E A=.06 P[$ rmsea $\leq 0.05]<0.001 ;$ SRMR $=.06)$. Good internal consistency was obtained for the items assessing somatization $(\alpha=.72)$, anxiety $(\alpha=.77)$ and depression $(\alpha=.84)$.

\subsection{Preliminary results}

\subsubsection{Descriptive statistics for the study variables}

Table 4 summarizes the means, standard deviations, range and correlations between the study variables. The correlation matrix of the study variables was examined. The exam of the mean scores show that, in general, students feel their needs more satisfied than frustrated, being relatedness the need more satisfied, and autonomy the need more frustrated. In terms of adjustment, and, as expected from a normative sample, students scored higher on SWB and subjective vitality than on anxiety, depression and somatization. The exam of the correlation matrix show that the three need satisfaction scores positively related to SWB and subjective vitality, and negatively related to depression, somatization and anxiety. In turn, the three need frustration scores were positively related to anxiety, depression and somatization and negatively related to SWL and subjective vitality. The correlations between SWL and subjective vitality, and also between anxiety, depression and 
Table 4

Means, standard deviations, range and correlations between the study variables (Study 2).

\begin{tabular}{|c|c|c|c|c|c|c|c|c|c|c|c|c|c|c|}
\hline & \multicolumn{14}{|c|}{ Zero-order correlations } \\
\hline & Mean & SD & Range & 1 & 2 & 3 & 4 & 5 & 6 & 7 & 8 & 9 & 10 & 11 \\
\hline Autonomy satisfaction & 4.05 & .68 & $1-5$ & 1 & & & & & & & & & & \\
\hline Competence satisfaction & 3.82 & .66 & $1-5$ & $.42^{* *}$ & 1 & & & & & & & & & \\
\hline Relatedness satisfaction & 4.25 & .67 & $1-5$ & $.43^{* *}$ & $.42^{* *}$ & 1 & & & & & & & & \\
\hline Autonomy frustration & 3.20 & .88 & $1-5$ & $-.34^{* *}$ & -.08 & $-.32^{* *}$ & 1 & & & & & & & \\
\hline Competence frustration & 2.66 & 1.06 & $1-5$ & $-.38^{* *}$ & $-.31^{* *}$ & $-.34^{* *}$ & $-.57^{* *}$ & 1 & & & & & & \\
\hline Relatedness frustration & 2.40 & 1.05 & $1-5$ & $-.16^{* *}$ & $-.42^{* *}$ & $-.44^{* *}$ & $.38^{* *}$ & .05 & 1 & & & & & \\
\hline Subjective well-being & 4.67 & 1.15 & $1-5$ & $.29^{* *}$ & $.23^{* *}$ & $.33^{* *}$ & $-.23^{* *}$ & $-.35^{* *}$ & .09 & 1 & & & & \\
\hline Subjective vitality & 3.74 & .86 & $1-5$ & $.29^{* *}$ & $.30^{* *}$ & $.32^{* *}$ & $-.22^{* *}$ & $-.19^{* *}$ & $-.16^{* *}$ & $.51^{* * *}$ & 1 & & & \\
\hline Somatization & 1.69 & .74 & $1-5$ & $-.10^{*}$ & .01 & -.04 & $.25^{* *}$ & $.19^{* *}$ & $.12^{*}$ & $-.17^{* *}$ & $-.17^{* *}$ & 1 & & \\
\hline Depression & 1.97 & .87 & $1-5$ & $-.18^{* *}$ & $-.14^{* *}$ & $-.21^{* *}$ & $.30^{* *}$ & $.39^{* *}$ & .03 & $-.50^{* *}$ & $-.39^{* *}$ & $.49^{* *}$ & 1 & \\
\hline Anxiety & 1.96 & .79 & $1-5$ & -.07 & -.02 & -.06 & $.24^{* *}$ & $.24^{* *}$ & $.11^{*}$ & $-.26^{* *}$ & $-.21^{* *}$ & $.70^{* *}$ & $.64^{* *}$ & 1 \\
\hline
\end{tabular}

$* p<.05$.

** $p<.01$.

somatization were positive and high, whereas the associations between well-being and ill-being indicators were negative and high (all correlations with $R<.9 ;$ VIF $<5$ ).

\subsection{Primary results}

\subsubsection{Confirmatory factor analysis}

CFA results cross-validated the good fit of Model 4 across all the fit indices considered $\chi^{2}(120)=269.32, p<.001 ; C F I=.95 ; G F I=.94$; $R M R=.05 ; R M S E A=.05 P[$ rmsea $\leq 0.05]<0.001$. No error crossvariances or threats to reliability or validity were identified for any of the six scales (see Table 4).

\subsubsection{Hierarchical regression analysis}

Hierarchical multiple regression analyses (HMR) were performed to examine whether the three need frustration scores predict unique variance on SWL, subjective vitality, anxiety, depression and somatization, over and above need satisfaction. In a first step autonomy, competence and relatedness satisfaction were entered as predictors. In a second step autonomy, competence and relatedness frustration were added to the prediction. Step 1 findings showed that the satisfaction of the three needs positively predicted $\operatorname{SWL} F(3,456)=26.80 ; p<.001$ and subjective vitality $F(3,456)=23.89 ; p<.001$ (for $\beta$ values see Fig. 2 ), whereas autonomy and relatedness satisfaction negatively predicted depression $(\beta=-.14, p=.001 ; \beta=-.14, p=.001)$. Model 1 explained $15 \%$ of variance in SWL, $14 \%$ in subjective vitality and $7 \%$ in depression. Step 2 findings show that, after controlling for the satisfaction of the three needs, Model 2, with need frustration included, explained 24\% the total variance in SWB, $(F(3456)=26.80 ; \mathrm{p}<.001), 15 \%$ in subjective vitality $(F(3456)=23.89 ; \mathrm{p}<.001), 27 \%$ in depression $(F(3456)=$ $27.38 ; \mathrm{p}<.001), 11 \%$ in anxiety $(F(3456)=9.37 ; \mathrm{p}<.001)$, and $8 \%$ in somatization $(F(3456)=6.80 ; \mathrm{p}<.001)$. Thus, the introduction of the three need frustration variables explained an additional $20 \%$ variance in depression, $10 \%$ in anxiety, and $6 \%$ in somatization, but also $9 \%$ of SWL and only $1.7 \%$ in subjective vitality. The frustration of the three needs significantly added value to the prediction of all three variables $(p<.001)$, particularly of depression $\left(R^{2}\right.$ Change $=.20 ; \mathrm{F}(6,453)=$ $27.38 ; \mathrm{p}<.001)$. In the final model the three need satisfaction scores become non-significant predictors of anxiety, depression and somatization $(p>.05)$.

\subsubsection{Multivariate regression analysis}

Fig. 2 presents the structural coefficients associated with the multivariate multiple regression model. We performed multivariate multiple regression analyses (MMR) on the BMPN data to inspect whether the scores of need satisfaction and need frustration predicted unique variance for well/ill-being outcomes after controlling for reciprocal associations. The variables examined followed the criteria defined for the normal distribution $(|s k|<3)$; $|k u<10|$ Finney \& DiStefano, 2006). As expected, autonomy, competence and relatedness satisfaction positively predict SWL and subjective vitality, whereas the frustration of the three needs positively predict anxiety, depression and somatization (see Fig. 2 for complete $\beta$ values). Curiously, autonomy frustration was found unrelated to depression ( $b$ AutFru.Dep $=.041 ; S E b=.037$, $\mathrm{Z}=1.11 ; p=.27$ ) and to anxiety ( $b$ AutFru.Anx $=.050 ;$ SEb $=.041$, $Z=1.20 ; p=.23$ ). In addition, competence and relatedness frustration negatively predicted SWL and subjective vitality, whereas the satisfaction of the three needs was not significantly related to anxiety, depression and somatization. As expected in SDT (Vansteenkiste \& Ryan, 2013) the crossover negative associations were lower-sized than the positive symmetrical relations.

\section{Discussion}

This study examined the dimensionality and psychometric properties of the BMPN in a sample of Portuguese high school students (Study 1) and inspected the criterion-related validity of the scales from an independent sample of high school students (Study 2). Findings were interpreted from Self-Determination Theory. Implications are now discussed for both research and practice in education.

In Study 1 we summarized the steps to develop the Portuguese version of the BMPN and the analytic procedures selected to examine the dimensionality and validity of the preferred model of scales. EFA performed on the 18-item BMPN extracted six correlated, but distinct factors distinguishing the scales assessing the satisfaction and frustration for autonomy, competence and relatedness needs. In subsequent CFAs we found that the models that somehow distinguished the components of satisfaction and frustration of basic needs (Model 2, 3, and 4) fitted better the data than the model that envisioned both components as opposite dimensions (Model 1) supporting H1a. CFA findings also support $\mathrm{H} 1 \mathrm{~b}$, when they show the progressive better fit from models that organize need satisfaction and need frustration as two distinct components (Models 2 and 3 ) to the model that distinguishes the components of satisfaction and frustration for each need (Model 4). Indeed, Model 4 yielded a comparatively better fit than the other models across all the fit indices considered. In addition, the lowest AIC estimates were obtained for Model 4, along with the absence of threats to the convergent and discriminant validity of the six scales. Therefore we preferred the sixfactor solution to interpret the structural organization of the BMPN items (support for $\mathrm{H} 2$ ). These findings further suggest that the three frustration BMPN subscales can be examined in separate, what is in line with recent studies suggesting that that the satisfaction and frustration forms of the needs may be substantive and distinguishable in and of themselves (Bartholomew et al., 2011; Sheldon \& Gunz, 2009; Sheldon, 2011; Sheldon \& Hilpert, 2012; Vlachopoulos \& Michailidou, 2006).

Study 2 replicated the CFA on Model 4, and inspected the criterionrelated validity of the six BMPN scales. Inspection of the mean scores indicated that, in general, Portuguese high school students report more 


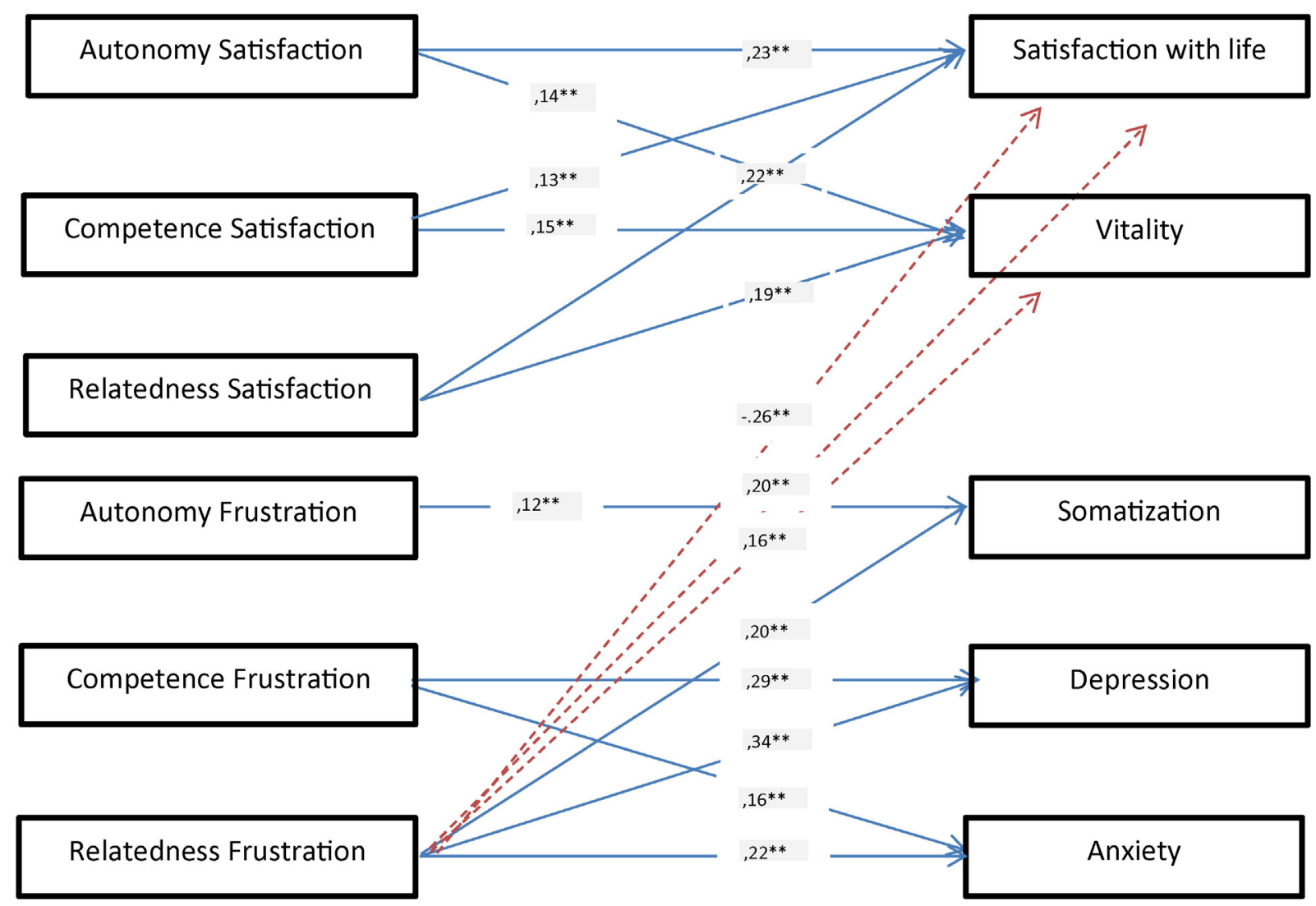

Note: Coefficients shown are standardized coefficients. Solid lines correspond to primary effects; Dashed lines indicate crossover effects. $* * \mathrm{p}<.001$

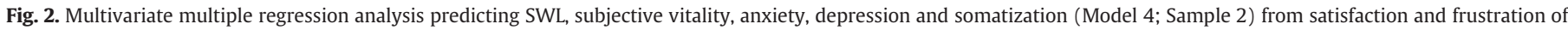
psychological needs.

need satisfaction than frustration, with competence being the least satisfied and autonomy being the most frustrated need. Hence, the social, and namely educational environments, and particularly teachers, as primary socialization agents, should differentially promote competencesupportive behaviors, that reinforce feelings of competence on students. Competence support is attained when teachers (a) provide clear and consistent expectations about involvement and achievement, (b) set clear and straightforward rules for class-related behavior and performance, (c) actively monitor class-related behavior, and (d) provide positive informational feedback for personal and effort-based progress (e.g., Deci \& Ryan, 2000; Grolnick, Benjet, Kurowski, \& Apostoleris, 1997).

In parallel, teachers would benefit from learning on how to refrain from actively using controlling behaviors that thwart the students' volitional functioning and result in subjective experiences of need frustration (e.g., Reeve \& Jang, 2006; Reeve, 2009). Autonomy thwart is conveyed when teachers use externally controlling tactics, such as punishment, yelling, "you must" or "you have to" expressions (Soenens \& Vansteenkiste, 2010), but also when teachers refrain from using psychological controlling strategies such as guilt-induction, shaming, instilling anxiety, attention withdrawal and normative comparisons for whenever students do not comply with their expectations, standards for achievement and for behavior (Soenens, Sierens, Vansteenkiste, Dochy, \& Goossens, 2012).

The HMR findings also show that frustration of the three needs predicted unique variance on well/ill-being indicators (Bartholomew et al., 2011) over and above need satisfaction (support for H3). Additionally, findings on regression analyses showed that the satisfaction of each need positively related to students' well-being (support for $\mathrm{H3a}$ ), whereas the frustration of each need was uniquely related to ill-being (support for H3b), after controlling for reciprocal effects. As expected, after controlling for need frustration, need satisfaction could not predict ill-being (support for H3c), whereas need frustration predicted both illbeing and diminished well-being on students (support for H3d). To explain this non-significant effect, subsequent HMR analyses found that autonomy and relatedness satisfaction negative relate to depression in step 1 but this association was reduced to non-significance when need frustration was added to the model in step 2. These findings are consistent with the SDT assumption that the lack of needs fulfillment would not necessarily entail the experience of ill-being, while experienced need frustration, by definition, blocks the possibility of needs fulfillment resulting on the experience of ill-being and diminished well-being (Vansteenkiste \& Ryan, 2013). For instance, students 'feelings of depression may arise from both perceptions of lack of nurturing relations (relatedness frustration) and/or feelings of being actively rejected (relatedness frustration) by primary socialization figures, such as teachers. However, the experience of being actively rejected, not only involves, by inherence, the perception of lacking warm, intimate connections, but also produces consequences far more severe in adjustment, over and above the low satisfaction of the three needs.

These particular findings underline the importance of not equating need frustration as need dissatisfaction of low satisfaction. They also stress the pervasive and severe implications that the inner feelings of competence and relatedness frustration have on students' maladjustment, what has important implications for education, and particularly for the teaching/learning process. In fact, they suggest the need to develop teacher-training programs that help teachers flag the students' problematic "signs" that are differentially associated to the adolescents" 
experiences of competence and relatedness frustration, but also clarify the nature of teacher behaviors that actively thwart these needs and their consequences for students' maladjustment, problem behaviors and underachievement. Specifically, teachers should be helped to identify and hinder from using competence and relatedness need thwarting behaviors within class settings. Competence thwarting is conveyed, for instance, when teachers give negative feedback about the student's performance in front of classmates, or compare the student's performance unfavorably to classmates (e.g. Soenens et al., 2012). These attitudes hamper the growth of self-efficacy beliefs and make students feel incompetent, incapable to set or successfully accomplish academic goals or standards for achievement. Behaviors that thwart relatedness are typical of teachers that actively reject or show dislike for the student (Deci \& Ryan, 1985) undermining feelings of social acceptance and connectedness and increasing his/her vulnerability to experience social exclusion and loneliness. Interventions targeted at diminishing such need thwarting practices are expected to increase awareness about the teacher's responsibility in maintaining and/or lowering or removing students' difficulties and as means to break up the vicious cycles of need frustration and maladjustment (e.g., Haerens et al., 2015). They should also provide teachers with effective tools in order to adjust instruction and learning strategies according to the students' individual differences. Future longitudinal studies are required to evaluate the efficacy of these types of interventions.

Against the background of the implications for education, it is not totally clear whether satisfaction and frustration are traits or method factors, although the data favor the trait approach. However, the findings that the six-factor solution best-fitted the BMPN data, the absence of threats detected for reliability and validity and the unique predictive value of need frustration of each need to predict ill-being, support the notion that, beyond discussing whether the satisfaction and frustration of each are methods versus traits, there is practical utility to examine the unique effects of these components separately (as suggested by Sheldon \& Hilpert, 2012), particularly to predict ill-being outcomes (Deci \& Ryan, 2000).

Our study presents some limitations. First, the cultural and sampling specificities may not only exemplify two confounding variables to be controlled for, but they can themselves represent alternative explanations for the results found. Additional cross-cultural studies are necessary to document the significance of the cultural/sampling bias on the results. Second, the cross-sectional nature of the data prevented from drawing causal links between the study variables. More prospective longitudinal data is necessary to capture the specific links and universal dynamics underlying the effects of basic needs on well/ill-being (e.g., Boone, Vansteenkiste, \& Soenens, 2014). Importantly, the longitudinal studies should target earlier developmental periods, since we know that higher scores of need frustration and ill-being are related to early school drop-out and heightened incidence of early psychiatric problems. Third, the use of two normative samples of relatively homogeneous and well-educated high school students limited the representativeness and generalization of the results to the broader population. It would be advantageous for future studies to use data from both normative, at-risk and dropped out students, to allow for a more clear understanding of how teacher' attitudes are related to the frustration of specific needs to predict the development problem behaviors, (mal) adjustment, school failure and early drop-out.

\section{Conclusion}

Taken together, the results support the construct validity of the BMPN, adding critical evidence for the factorial distinctiveness of the need satisfaction and frustration components of basic psychological needs, which is in line with the conceptual argument of the substantive distinction between the satisfaction and frustration dimensions of basic needs. This approach is of major relevance to testify for the true dimensionality of the need constructs, associated to the "bright" and "dark" sides of human experience, helping to bridge the gap between remedial-oriented and strength-oriented frameworks and interventions in education (Vansteenkiste \& Ryan, 2013).

\section{References}

Adie, J., Duda, J. L., \& Ntoumanis, N. (2008). Autonomy support, basic need satisfaction and the optimal functioning of adult male and female sport participants: A test of basic needs theory. Motivation and Emotion, 32, 189-199. http://dx.doi.org/10.1007/ s11031-008-9095-z.

Bartholomew, K. J., Ntoumanis, N., Ryan, R. M., \& Thøgersen-Ntoumani, C. (2011). Psychological need thwarting in the sport context: Assessing the darker side of athletic experience. Journal of Sport and Exercise Psychology, 33, 75-102.

Bentler, P. M., \& Wu, E. J. C. (2002). EQS for Windows user's guide. Encino, CA: Multivariate Software, Inc.

Baumeister, R. F., \& Leary, M. R. (1995). The need to belong: Desire for interpersonal attachments as a fundamental human motivation. Psychological Bulletin, 117, 497-529. http://dx.doi.org/10.1037//0033-2909.117.3.497.

Boone, L., Vansteenkiste, M., \& Soenens, B. (2014). Self-critical perfectionism and binge eating symptoms: A longitudinal test of the intervening role of psychological need frustration. Journal of Counseling Psychology, 61(3), 363-373. http://dx.doi.org/10. 1037/a0036418.

Byrne, B. M. (2010). Structural equation modeling with AMOS (2nd ed.). New York: Rutledge.

Canavarro, M. C. (2007). Inventários de Sintomas Psicopatológicos: Uma revisão crítica dos estudos realizados em Portugal. In M. R. Simões, C. Machado, G. Gonçalves, \& L. Almeida (Eds.), Avaliação psicológica: Instrumentos validados para a população PortuguesaPsychological assessment: instruments validated for the Portuguese Population. Quarteto Editora: Coimbra.

Chen, B., Vansteenkiste, M., Beyers, W., Boone, L., Deci, E. L., Deeder, J., ... Verstuyf, J. (2015). Psychological need satisfaction and desire for need satisfaction across four cultures. Motivation and Emotion, 39(2), 216-236. http://dx.doi.org/10.1007/s11031-014-9450-1.

Cheung, G. W., \& Rensvold, R. B. (2002). Evaluating goodness-of-fit indexes for testing MI. Structural Equation Modeling, 9, 235-255.

Deci, E. L., \& Ryan, R. M. (1985). Intrinsic motivation and self-determination in human behavior. New York: Plenum.

Deci, E. L., \& Ryan, R. M. (2000). The "What" and "Why" of goal pursuits: Human needs and the self-determination of behavior. Psychological Inquiry, 11, 227-268. http:// dx.doi.org/10.1207/S15327965PLI1104_01.

Deci, E. L., \& Ryan, R. M. (2008). Facilitating optimal motivation and psychological wellbeing across life's domains. Canadian Psychology, 49, 14-23. http://dx.doi.org/10. 1037/0708-5591.49.1.14.

Derogatis, L. (2001). Brief Symptom Inventory (BSI)-18. Administration, scoring and procedures manual. Minneapolis: NCS Pearson, Inc.

Diener, E., Emmons, R. A., Larsen, R. J., \& Griffin, S. (1985). The satisfaction with life scale. Journal of Personality Assessment, 49, 71-75. http://dx.doi.org/10.1207/ s15327752jpa4901_13.

Finney, S. J., \& DiStefano, C. (2006). Nonnormal and categorical data in structural equation models. In G. R. Hancock, \& R. O. Mueller (Eds.), A second course in structural equation modeling (pp. 269-314). Greenwich, CT: Information Age.

Fornell, C., \& Larcker, D. F. (1981). Evaluating structural equation models with unobservable variables and measurement error. Journal of Marketing Research, 48, 39-50. http://dx.doi.org/10.2307/3151312.

Grolnick, W. S., Benjet, C., Kurowski, C. O., \& Apostoleris, N. (1997). Predictors of parent involvement in children's schooling. Journal of Educational Psychology, 89, 538-548.

Haerens, L. Aelterman, N., Vansteenskiste, M., Soenens, B., \& Petegen, S. (2015). Do perceived autonomy-support and controlling teaching relate to physical education students' motivational experiences through unique pathways? Distinguishing between the bright and dark side of motivation. Psychology of Sport and Exercise, 16, 26-36.

Hambleton, R. K. (2001). The next generation of the ITC test translation and adaptation guidelines. European Journal of Psychological Assessment, 17, 164-172. http://dx.doi. org/10.1027//1015-5759.17.3.164.

Hodge, K., Lonsdale, C., \& Ng, J. Y. Y. (2008). Burnout in elite rugby: Relationships with basic psychological needs fulfilment. Journal of Sports Sciences, 26, 835-844.

Hu, L. T., \& Bentler, P. M. (1999). Cutoff criteria for fit indexes in covariance structure analysis: Conventional criteria versus new alternatives. Structural Equation Modeling, 6(1), 1-55. http://dx.doi.org/10.1080/10705519909540118.

Kline, R. B. (2005). Principles and practice of structural equation modeling (2nd ed.). New York: The Guilford Press.

Lemos, M. S., Gonçalves, T., \& Coelho, C. (2011). Avaliação do bem-estar dos estudantes: adaptação de uma Escala Vitalidade Subjectiva [Assessment of students' well-being: adaptation of a subjective vitality scale]. In A. S. Ferreira, A. Verhaeghe, D. R. Silva, L. S. Almeida, R. Lima, \& S. Fraga (Eds.), Actas do VIII Congresso Iberoamericano de Avaliação/Evaluación Psicológica e XV Conferência Internacional Avaliação Psicológica (pp. 1929-1935).

McIver, J. P., \& Carmines, E. G. (1981). Unidimensional scaling. Thousand Oaks, CA: Sage.

Preacher, K. J., \& Hayes, A. F. (2004). SPSS and SAS procedures for estimating indirect effects in simple mediation models. Behavior Research Methods, Instruments, and Computers, 36, 717-731. http://dx.doi.org/10.3758/BF03206553.

Quested, E., \& Duda, J. L. (2010). Exploring the social-environmental determinants of well- and ill-being in dancers: A test of Basic Needs Theory. Journal of Sport and Exercise Psychology, 32, 39-60.

Reeve, J. (2009). Why teachers adopt a controlling motivating style toward students and how they can become more autonomy supportive. Educational Psychologist, 44, 159-178. 
Reeve, J., \& Jang, H. (2006). What teachers say and do to support students' autonomy during learning activities. Journal of Educational Psychology, 98, 209-218.

Reis, H. T., Sheldon, K. M., Gable, S. L., Roscoe, J., \& Ryan, R. M. (2000). Daily well-being: The role of autonomy, competence, and relatedness. Personality \& Social Psychology Bulletin, 26, 419-435. http://dx.doi.org/10.1177/0146167200266002.

Ryan, R. M. (1995). Psychological needs and the facilitation of integrative processes. Journal of Personality, 63, 397-427. http://dx.doi.org/10.1111/j.1467-6494.1995.tb00501.x.

Ryan, R. M. \& Deci, E. L. (2000). Self-determination theory and the facilitation of intrinsic motivation, social development, and well-being. American Psychologist, 55, 68-78. http://dx.doi.org/10.1037/0003-066X.55.1.68.

Ryan, R. M., \& Frederick, C. M. (1997). On energy, personality and health: Subjective vitality as a dynamic reflection of well-being. Journal of Personality, 65, 529-565. http://dx. doi.org/10.1111/j.1467-6494.1997.tb00326.x.

Schunk, D. H., \& Zimmerman, B. J. (2006). Influencing children's self-efficacy and selfregulation of reading and writing through modelling. Reading and Writing Quarterly, 23(1), 7-25. http://dx.doi.org/10.1080/10573560600837578.

Sheldon, K. M. (2011). Integrating behavioral-motive and experiential requirement perspectives on psychological needs: A two process model. Psychological Review, 118, 552-569. http://dx.doi.org/10.1037/a0024758.

Sheldon, K. M., \& Gunz, A. (2009). Psychological needs as basic motives, not just experiential requirements. Journal of Personality, 77, 1467-1492. http://dx.doi.org/10. 1111/j.1467-6494.2009.00589.x

Sheldon, K. M., \& Niemiec, C. (2006). It's not just the amount that counts: Balanced need satisfaction also affects well-being. Journal of Personality and Social Psychology, 91, 331-341. http://dx.doi.org/10.1037/0022-3514.91.2.331.

Sheldon, K. M., \& Hilpert, J. C. (2012). The balanced measure of psychological needs (BMPN) scale: An alternative domain general measure of need satisfaction. Motivation E Emotion. http://dx.doi.org/10.1007/s11031-012-9279-4.

Sheldon, K. M., Ryan, R. M. \& Reis, H. R. (1996). What makes for a good day? Competence and autonomy in the day and in the person. Personality and Social Psychology Bulletin, 22, 1270-1279. http://dx.doi.org/10.1177/01461672962212007.
Simões, A. (1992). Ulterior validação de uma escala de satisfação com a vida (SWLS). Revista Portuguesa de Pedagogia, XXVI (3). (pp. 503-515).

Soenens, B., \& Vansteenkiste, M. (2010). A theoretical upgrade of the concept of parental psychological control: Proposing new insights on the basis of self-determination theory. Developmental Review, 30, 74-99. http://dx.doi.org/10.1016/j.dr.2009.11.001.

Soenens, B., Sierens, E., Vansteenkiste, M., Dochy, F., \& Goossens, L. (2012). Psychologically controlling teaching: Examining outcomes, antecedents, and mediators. Journal of Educational Psychology, 104(1), 108-120.

Tabachnick, B. G., \& Fidell, L. S. (2007). Using multivariate statistics (5th ed.). Boston: Pearson Education, Inc.

Tinsley, H. E. A., \& Tinsley, D. J. (1987). Uses of factor analysis in counseling psychology research. Journal of Counseling Psychology, 34, 414-424. http://dx.doi.org/10.1037// 0022-0167.34.4.414.

Vansteenkiste, M., \& Ryan, R. M. (2013). On psychological growth and vulnerability: Basic psychological need satisfaction and need frustration as a unifying principle. Journal of Psychotherapy Integration, 23, 263-280. http://dx.doi.org/10.1037/a0032359.

Vansteenkiste, M., Lens, W., Soenens, B., \& Luyckx, K. (2006). Autonomy and relatedness among Chinese sojourners and applicants: Conflictual or independent predictors of well-being and adjustment? Motivation and Emotion, 30, 273-282. http://dx.doi.org/ 10.1007/s11031-006-9041-X.

Verstuyf, J., Vansteenkiste, M., Soenens, B., Boone, L., \& Mouratidis, A. (2013). Daily ups and downs in women's binge eating symptoms: The role of basic psychological needs, general self-control, and emotional eating. Journal of Social and Clinical Psychology, 32, 335-361.

Vlachopoulos, S. P., \& Michailidou, S. (2006). Development and initial validation of a measure of autonomy, competence, and relatedness in exercise: The basic psychological needs in exercise scale. Measurement in Physical Education and Exercise Science, 10, 179-201. http://dx.doi.org/10.1207/s15327841mpee1003_4. 